\title{
GEOMETRIA NA FORMAÇÃO DAS NORMALISTAS DO INSTITUTO SANTA MARTA NO MUNICÍPIO DE BARRA DO GARÇAS (1960 - 1980)
}

\author{
GEOMETRY IN THE FORMATION OF NORMALISTS AT THE SANTA MARTA \\ INSTITUTE IN THE MUNICIPALITY OF BARRA DO GARÇAS (1960 - 1980)
}

DOI: 10.23926/RPD.2526-2149.2020.v5.n2.p626-651.id691

\section{Marta Maria Gama \\ Mestra em Ensino (UNIC) \\ Docente na UniCathedral - \\ Barra do Garças/MT \\ mgpedagoga@hotmail.com}

\section{Laura Isabel Marques Vasconcelos de}

\section{Almeida}

Doutora em Educação

(PUC/PR)

Docente do Programa de

Pós-Graduação em Ensino da Universidade de Cuiabá (UNIC)

lauraisabelvasc@hotmail.co $\underline{\mathrm{m}}$

\section{Neuza Bertoni Pinto \\ Doutora em Educação (USP) Docente Colaboradora do Programa de Pós-Graduação em Educação em Ciências e Matemática - REAMEC (UFMT/UFPA/UEA) neuzabertonip@gmail.com}

Resumo: Este artigo é parte da Pesquisa de Mestrado do Programa de Pós-Graduação da Universidade de Cuiabá e tem como objeto de estudo o ensino de geometria na formação de professoras normaliatas do ensino primário em Barra do Garças/MT. Ancorada na abordagem histórico-cultural, o estudo fundamentou-se nos aportes teóricos de Chervel (1990), De Certeau (1982), Julia (2001), Pinto (2014) e Silva; Valente (2014). Teve como objetivo analisar a presença da geometria na formação das normalistas que cursaram o magistério e lecionaram no Instituto Santa Marta no período delimitado da pesquisa. As fontes foram constituídas pelos depoimentos e diários de classe com ênfase no ensino da geometria na escola primária. Os dados revelam a presença da geometria indicando como as normalistas aprendiam e ensinavam os conceitos geométricos em sala de aula, possibilitando novas indagações e reflexões frente ao descaso das escolas pela disciplina.

Palavras-chave: Ensino de geometria. História da educação matemática. Formação de professores. Escola primária.

\begin{abstract}
This article is part of the Master's Research of the Graduate Program of the University of Cuiabá and its object of study is the teaching of geometry in the formation of normal teachers of primary education in Barra do Garças. Anchored in the historicalcultural approach, the study was based on the theoretical contributions of Chervel (1990), De Certeau (1982), Julia (2001), Pinto (2014) and Silva; Valente (2014). It aimed to analyze the presence of geometry in the training of normalists who attended the teaching and taught at the Santa Marta Institute in the limited period of the research. The sources were constituted by statements and class diaries with an emphasis on teaching geometry in primary school. The data reveal the presence of geometry, indicating how normalists learned and taught geometric concepts in the classroom, enabling new questions and reflections in the face of the neglect of schools by the discipline.

Keywords: Geometry teaching. History of mathematical education. Teacher training. Primary school.
\end{abstract}




\section{INTRODUÇÃO}

O artigo destaca parte da pesquisa de Mestrado em Ensino do Programa de PósGraduação da Universidade de Cuiabá/UNIC em associação ampla com o Instituto Federal de Educação, Ciência e Tecnologia de Mato Grosso/IFMT. A investigação insere-se nos estudos da História da Educação Matemática com o objetivo de analisar a presença da Geometria na formação de professores primários do Instituto Santa Marta em Barra do Garças/MT - (19601980).

Esse período justifica-se pela criação do referido Instituto, com vistas a ofertar o Curso Normal e formar os primeiros professores da região. $O$ intento foi analisar as formas de apropriação da geometria no sentido proposto por Chartier (1990), buscando-se investigar o papel de pedagogias diferentes que tiveram lugar durante o período e que poderiam justificar mudanças no seu tratamento metodológico.

O interesse pela temática emerge durante a trajetória profissional, como professora da Educação Básica, porém, ao ingressar no Mestrado a proximidade com o tema tornou-se realidade. As primeiras leituras sobre a Educação Matemática trouxeram à tona lembranças de possíveis lacunas que ficaram durante esse trajeto, contribuindo para inúmeras indagações ao longo da carreira docente que acompanharam durante décadas, a vida de muitos alunos e professores formadores, tendo em vista que as dificuldades ainda estão presentes na realidade educacional.

Ao assumir o ofício de historiadora foi possível conhecer a produção de um determinado período que fora constituído pela cultura escolar motivando a busca incessante de compreender como a geometria era ensinada nas escolas primárias de Mato Grosso em contextos diferentes. Esse conteúdo foi relegado ao segundo plano, ora pela dificuldade de compreensão, ora por ministrar um conteúdo de forma abstrata considerado muitas vezes sem significado e distanciado da realidade.

Outro aspecto inerente à opção pelo tema se deve às escassas produções específicas sobre o ensino da geometria em Mato Grosso nas décadas de 1960 a 1980, ponderando que a disciplina oferece um vasto campo de ideias férteis para aprendizagem e o raciocínio lógico, métodos de muito valor quando se trata do desenvolvimento intelectual do aluno e da passagem das operações concretas para as abstratas. Considerando ainda, que a geometria desempenha papel primordial no ensino, porque a intuição, o formalismo, a abstração e a dedução constituem a sua essência (FAINGUELERNT, 1995 p.45). 
Neste contexto, as pesquisadoras tomaram como objeto de estudo a geometria e sagrouse a seguinte questão: De que forma a geometria esteve presente na formação de professores primários do Instituto Santa Marta em Barra do Garças, nas décadas de 1960 a 1980 ? Em busca de respostas, emergimos na dimensão metodológica da abordagem histórico cultural que fundamentou-se nos aportes teórico-metodológico da História Cultural e contribuições de autores e historiadores renomados.

Para responder o problema de pesquisa, inventariamos fontes históricas (Programas de ensino, livros didáticos e diários de classe) ligadas ao cotidiano escolar do período delimitado nos arquivos públicos, escolares e depoimentos de protagonistas que durante sua trajetória escolar estudaram na instituição e posteriormente tornaram-se professoras primárias. Atualmente essas profissionais encontram-se aposentadas e apenas uma das depoentes continua na ativa desempenhando a função de professora da referida instituição.

Entretanto, faz-se necessário revisitar o período que antecede a pesquisa para contextualizarmos a relevância das Salesianas que contribuíram sobremaneira com o avanço e progresso na cidade de Barra do Garças/MT. Em 1956, as Irmãs Salesianas chegam ao município e com apoio da comunidade local, muito trabalho e dedicação se engajaram na missão de ofertar aos estudantes da região, professores qualificados, transformando a realidade educacional. Após muitas lutas, no ano de 1967,cria-se o Instituto Santa Marta que pertence a Inspetoria Nossa Senhora da Paz de Cuiabá, com a finalidade de atender a comunidade local e formar "Professoras Normalistas" no Curso de Magistério, dirigido pelas Irmãs Salesianas Dom Bosco.

Sabe-se que os colégios salesianos foram fundamentais para a educação em toda região mato-grossense, considerando que neste período, o Estado de Mato Grosso enfrentava muitos desafios por ser distante dos grandes centros e conforme aponta Bittar (2001), esse fator geográfico dificultava o desenvolvimento territorial tanto em nível econômico, quanto educacional.

Visando expandir a ocupação da imensidão de terras em solo brasileiro, o presidente Getúlio Vargas (1937-1946) em pleno Estado Novo ${ }^{1}$, instituiu o movimento denominado

\footnotetext{
${ }^{1}$ Estado Novo ou Terceira República Brasileira, foi o regime político brasileiro instaurado por Getúlio Vargas em 10 de novembro de 1937 que vigorou até 31 de janeiro de 1946. Era caracterizado pela centralização do poder, nacionalismo, anticomunismo e por seu autoritarismo.
} 
"Marcha para o oeste" com o intento de povoar diversas regiões do país. Neste cenário, Mato Grosso se torna alvo de grande entrada migratória, beneficiando o aparecimento de novos povoamentos e posteriormente novos distritos e municípios.

A partir desse evento a carência de escolas tornou-se uma dificuldade a ser encarada, como evidencia Bittar (2001), os novos números da população deram a padre Ernesto Carletti, então inspetor salesiano na região, a chance de incentivar e expandir a ação escolar. Hoje percebe-se visivelmente que os colégios salesianos marcaram a vida das cidades onde foram construídos, tornando-se referência educacional para a vida e desenvolvimento da comunidade local (MISSÃO EM NOTÍCIA, 2002, p. 2-4).

Com o aumento da oferta de vagas na educação, a formação de professores tornou-se uma necessidade no Brasil, em Mato Grosso não foi diferente, embora a Escola Normal tenha passado por muitas idas e vindas. Criada por meio da Lei Provincial n ${ }^{\circ}$ 8, de 5 de maio de 1837, a Escola Normal responsável pela formação de profissionais da educação funcionou por um breve período, sendo desativada em 9 de novembro de 1844. Somente após trinta anos, especificamente no ano de 1974, foi instituído novamente o curso Normal em Cuiabá.

No entanto, a demarcação temporal da pesquisa justifica-se pelas mudanças ocorridas em Mato Grosso e prediz um período de grandes mudanças no cenário educacional. Dessas variações decorreram amplas reformas, dentre elas, a criação da Lei de Diretrizes e Bases da Educação Nacional - LDBEN 4024/61, que reafirmou a Lei Orgânica do Ensino Normal por meio do Decreto-lei n. 8.530 em 2 de janeiro de 1946. Esse período também foi marcado pela criação da Lei de Diretrizes e Bases-LDB 5692/71, a qual prevê a obrigatoriedade da ampliação do ensino de quatro para oito anos de escolaridade com a fusão do primário e ginásio (SAVIANI, 2010).

Diante das premissas, situa-se o momento histórico educacional para melhor compreensão sobre a importância da geometria nas décadas delimitadas neste estudo para o ensino primário. Ao longo da carreira como docente dos anos iniciais, as inquietações se ampliam por entender que a formação do professor precisa estar imbuída do desejo que os futuros profissionais aprendam e se apropriem dos conteúdos necessários para ensinar os alunos em sala de aula. Esse olhar como pesquisadora possibilita um enfrentamento aos novos

\footnotetext{
${ }^{2}$ A "Marcha para o Oeste" idealizada pelo governo de Getúlio Vargas, fomentou a ocupação territorial da região Centro-Oeste. Vislumbrando o progresso, o governo estimulou a população para que migrassem para o centro do Brasil, onde havia muitas terras desocupadas.
} 
desafios, à medida que se compreende os avanços, rupturas e retrocessos que aconteceram ao longo dos anos na disciplina de Matemática, em especial no ensino de geometria.

\section{Metodologia Histórico-Cultural}

As primeiras leituras sobre a geometria remetem às lembranças de possíveis lacunas que sempre existiram e permearam a carreira docente, principalmente quando se constata a ausência de produções específicas relativas ao ensino dessa disciplina no Estado de Mato Grosso.

A pesquisa na vertente histórica vincula-se na abordagem metodológica históricocultural e fundamentou-se nos aportes teórico-metodológicos de historiadores e autores que abordam os conceitos de história da disciplina escolar (CHERVEL, 1990), Operação historiográfica (DE CERTEAU, 1994), Cultura escolar (JULIA, 2001), História da educação matemática (PINTO, 2014; e SILVA; VALENTE, 2014).

Vale ressaltar que nessa perspectiva metodológica, não há separação entre teoria e método. Conforme De Certeau (1982), a história é uma prática (uma disciplina), seu resultado (o discurso) e a relação de ambos (a produção). $\mathrm{O}$ autor destaca as fases que considera essenciais: a documental - busca de indícios, a explicativa e compreensiva - produção de explicação dos significados e por fim a escriturária - processo de elaboração do relato (DE CERTEAU, 1982, p.66).

$\mathrm{O}$ autor concebe a história como uma narrativa e como uma prática científica problematizada pelo ofício do historiador: "as premissas das quais o discurso não fala" e "as leis silenciosas que organizam o espaço produzido como texto" (DE CERTEAU, 1982, p. 65). Assim, a prática historiográfica possibilita a compreensão de uma forma de educação presente no espaço escolar e suas relações com o contexto social de um determinado momento histórico.

\footnotetext{
A pesquisa historiográfica se articula em função de um lugar de produção social, econômico, político e cultural e isso organiza a preferência por determinados métodos, as convenções disciplinares, a hierarquia de interesses, a constituição de objetos de investigação e, também, a existência de estranhas e vastas praias de silêncios (REVEL; DE CERTEAU; JULIA, 1989, p. 67).
}

Chervel (1990) contribui com a pesquisa quando aponta que o estudo histórico da Matemática exige considerar os produtos da cultura escolar de outros tempos, considerando os elementos que foram vistos e elaborados em contextos diferentes. As pesquisas do autor revelam que as disciplinas escolares são concepções oriundas do sistema escolar, "a escola constitui o lugar de criação das disciplinas" (1990, p.184). 
Destaca a importância de conhecer a história da disciplina sob a responsabilidade do professor. Esclarece que as disciplinas escolares estão sempre a serviço de uma determinada finalidade educativa, não se restringindo apenas aos ensinamentos explícitos e programados. "Seus fins não se encontram apenas nos textos oficiais e para conhecê-las é preciso compreender, por que a escola ensina, o que ensina, como ensina, indo à realidade pedagógica" (CHERVEL, 1990, p.190).

Desse modo, consideramos os estudos de Chervel como um importante referencial teórico-metodológico para quem pesquisa na vertente histórica, em específico sobre uma disciplina escolar. Para Valente $(2004$, p. 80$)$ as pesquisas sobre o ensino da disciplina de matemática foram revelando o que se poderia chamar de "uma necessidade de alargamento da compreensão de quais são os elementos que participam da produção/elaboração/constituição dos saberes escolares, em particular, da matemática escolar e sua história”. Segundo Valente (2004, p. 80) isso foi possível com a inclusão do conceito sistematizado pelo historiador Dominique Julia (2001).

No artigo "A cultura escolar como objeto histórico", Julia (2001) considera inicialmente, que ela não pode ser estudada sem a análise precisa das relações conflituosas ou pacíficas que ela mantém, a cada período de sua história, com o conjunto das culturas que lhe são contemporâneas: cultura religiosa, cultura política ou cultura popular. (2001, p. 10). A partir dos pressupostos dos autores supracitados as discussões em torno da geometria no primário, começaram a ser delineadas.

Embora as pesquisas sejam escassas o tema não é recente, a primeira legislação do ensino primário em 1827 levantou as primeiras argumentações sobre a preocupação com o ensino dessa matéria. De acordo com Silva e Valente (2014, p. 10) pesquisar o passado da geometria, contribui para analisar como as dinâmicas de transformações dessa matéria escolar chegam aos dias atuais.

No intuito de compreender a importância dada à geometria, naquele período, houve uma aproximação com as histórias das protagonistas, mais especificamente de suas experiências durante a formação acadêmica e depois como professoras primárias. Dessa forma, o objetivo foi analisar a presença da geometria na formação das normalistas e como ensinavam esse conteúdo em sala de aula.

Santos (2016) afirma que no período retratado, as Escolas Normais tinham a incumbência de formar professores para a escola primária e no Estado de Mato Grosso as instituições de ensino apresentavam condições precárias e ofereciam uma formação direcionada 
apenas para os métodos de ensino. Esse reducionismo na formação inicial dos professores e a subordinação do conhecimento ao domínio da didática comprometeram sobremaneira o fazer docente.

Ademais, nesse período havia muitos professores das escolas primárias que não tinham a formação específica para o magistério. Possuíam, segundo os estudos de Tardif (2010, p.48) saberes experienciais, "adquiridos e necessários no âmbito da prática da profissão e que não provêm das instituições de formação e nem dos currículos". Ensinavam da forma como aprendiam e se apegavam religiosamente ao livro didático, como único recurso essencial da prática pedagógica.

Tardif (2010, p.36) destaca que os saberes dos professores podem ser especificados: saberes profissionais, disciplinares, curriculares e experienciais. Tais saberes podem ser considerados como um saber plural, "sua prática integra diferentes saberes, como os quais o corpo docente mantém diferentes relações", ou seja, formado por conjunto de saberes (saberes profissionais, saberes disciplinares, saberes curriculares e saberes experienciais) que culmina na prática cotidiana do professor em sala de aula. Para o autor:

\footnotetext{
O saber não é uma coisa que flutua no espaço: o saber dos professores é o saber deles e está relacionado com a pessoa e a identidade deles, com a sua experiência de vida e com a sua história profissional, com as suas relações com os alunos em sala de aula e com os outros atores escolares na escola etc. Por isso é necessário estudá-lo relacionando-o com esses elementos constitutivos do trabalho docente. (TARDIF, 2008, p. 11)
}

Neste contexto, com a precariedade do ensino, o livro didático passa a fazer parte da rotina diária do professor e tudo indica que para vencer os desafios do seu ofício, se apoiava nesse recurso como uma ferramenta necessária ao processo de ensino e aprendizagem. Quanto aos conteúdos de geometria propostos no livro didático, com o Movimento da Matemática Moderna (MMM) na década de 1960, houve uma prevalência do rigor matemático.

Segundo Muniz (2017, p. 20) esse movimento "trouxe uma abordagem para a geometria baseada no raciocínio lógico, estruturas axiomáticas, processos dedutivos e promoveu uma reestruturação do ensino ao incluir na geometria euclidiana uma linguagem de conjuntos". A autora ainda ressalta que os professores sentiram-se despreparados para ministrar suas aulas e muitos suprimiam esses conteúdos dos planejamentos.

Não bastassem as mudanças curriculares, houve uma discriminação em relação à geometria quando passou a ocupar os últimos capítulos dos livros didáticos. Os fatos evidenciam o porquê de a geometria ainda ser uma das matérias mais secundarizadas da 
Matemática, embora atualmente, venha sendo auferido um lugar expressivo tanto em sala de aula, quanto nos capítulos iniciais dos livros didáticos.

Neste sentido, buscou-se analisar a presença da geometria na formação das normalistas em território mato-grossense, não se desviando da problemática política que envolve a educação desde os tempos de outrora, pois como diz Gramsci (1973, p.14), "agir dentro da escola é também agir na sociedade da qual ela não pode estar separada”.

\section{VESTÍGIOS DA GEOMETRIA NO CENÁRIO EDUCACIONAL BRASILEIRO}

A geometria surgiu na educação escolar brasileira em 1699, com a finalidade de "formar uma sólida base para futuros estudos de engenharia militar, navegação e arquitetura naval" (CASTRO, 1999, p.19). A partir desse evento, a disciplina passou a compor o currículo das primeiras escolas militares e as chamadas aulas de fortificação eram ministradas para formação do Engenheiro: oficial que servia à guerra para ataques, defesa e fortificação de praças (MOCROSKY; MONDINI; ESTEPHAN, 2012, p.3).

Portugal no século XVII enviou especialistas ao Brasil para capacitar pessoas em fortificações militares, a fim de defender suas terras criando assim, a Aula de Fortificação. Meneses (2007) relata que a Geometria ligada à guerra é a primeira forma de prática pedagógica que se tem registro no Brasil.

A primeira lei a aventar sobre a escola primária denominada "Elementar ou de Primeiras letras no Brasil", foi o Decreto Imperial de 15 de outubro de 1827, intitulado: "Manda crear escolas de primeiras letras em todas as cidades, villas e logares mais populosos do Império" (BRASIL, 1827, p.71). Conforme Meneses (2007) desde a criação do curso primário o que se ajuizava sobre o ensino da geometria, era fazer com que os alunos aprendessem a medir terrenos.

Ademais, Castro (1999) ressalta que a geometria não era tomada como conteúdo importante, já que sua primeira finalidade era proteger o país e a população de possíveis invasores, por isso passou a utilizar a geometria com intuito de levantar suas fortalezas.

A partir desse marco tornam-se frequentes no cenário acadêmico os estudos sobre a história das disciplinas escolares. Como destaca Bittencourt (2003), os estudos em História das disciplinas escolares surgiram em diferentes países quase ao mesmo tempo e com a mesma preocupação: “identificar a gênese e os diferentes momentos históricos em que se constituem os saberes escolares, visando perceber a sua dinâmica, as continuidades e descontinuidades no processo de escolarização" (BITTENCOURT, 2003, p.15). 
Chervel (1990) por outro lado, afirma que o campo da História das disciplinas escolares destaca o porquê da escola ensinar o que ensina, em vez de tentar objetar o que a escola necessitaria ensinar. $\mathrm{O}$ autor também avulta que as finalidades do ensino não estão explicitamente prescritas nos textos oficiais, tendo o pesquisador, a necessidade de buscar vestígios nas mais variadas fontes, contribuindo para a historiografia da disciplina escolar.

Neste caso, a realização desse ofício requer um contato com as fontes para a efetivação da pesquisa, uma referência às "testemunhas", sejam elas documentos, fotografias, cartas, quadros ou objetos de uma época, inquirindo-as, interpretando-as como Bloch (2001).

Silva e Valente (2014, p.21) na obra “A geometria nos primeiros anos escolares: história e perspectivas atuais" trazem discussões em torno das contestações sobre a geometria, apresentam dados da primeira legislação do ensino primário em 1827, a qual levantou debates registrados nos Anais da Câmara e do Senado que tratavam de pontos elementares acerca da preocupação com o ensino dessa disciplina.

Os autores afiançam que nas primeiras décadas do século XIX, a partir da tradução das Memórias de Condorcet, nasce o pensamento a respeito do ensino da geometria para o curso primário. A disciplina tinha caráter prático com vistas a atender as particularidades da agrimensura. Assim o ensino parte das construções de linhas, de ângulos, de figuras e, mesmo, dos desenhos em perspectiva de sólidos geométricos (SILVA; VALENTE, 2014).

Com vistas a participar do cenário educacional, Mato Grosso publica no Regulamento da Instrução Pública do Estado o Programa de Ensino Primário, em outubro de 1942. As disciplinas do Programa elencavam conceitos referentes à geometria distribuídos por série do Ensino Primário, a saber: "Leitura e Linguagem oral e escrita, Aritmética, Geografia, Ciências físicas e naturais, Educação higiênica, Instrução moral e cívica, Desenho, Trabalhos manuais e Canto.” (FERNANDES; BORGES, 2015, p.210). O ensino de geometria no primeiro, segundo e terceiro anos, segundo a instrução do Programa estaria voltada para o ensino do Desenho e não especifica nenhum conteúdo de Desenho e Geometria para os professores.

Vale lembrar que na década de 1940, uma política nacional para o ensino primário foi efetivada no Brasil, a chamada Lei Orgânica do Ensino Primário (Decreto Lei no 8.529 de 21/11/1946). O INEP (Instituto Nacional de Ensino e Pesquisa), em 1955 edita os Guias de Ensino para a escola primária, os quais foram apontados como um dos primeiros materiais de orientação didática do ensino primário para todo país. Em 1971 a Lei de Diretrizes e Bases (Lei 5692/71) institui o núcleo comum nacional para o Ensino Fundamental no país. (ALMEIDA, 2010, p.165). 
Antes da LDB 5692/71, Mato Grosso já tinha aprovado no ano de 1962, os Programas Escolares do Ensino Primário do Estado. As matrizes curriculares determinavam que a $1^{\mathrm{a}}, 2^{\mathrm{a}} \mathrm{e}$ $4^{\mathrm{a}}$ séries tivessem Desenho (desenho geométrico e desenho livre e espontâneo). Apenas na $3^{\mathrm{a}}$ série constavam Aritmética e Geometria como sendo uma disciplina e Desenho outra disciplina, conforme destaca a Figura 1.

Figura 1 - Programas Escolares do Ensino Primário, 1962

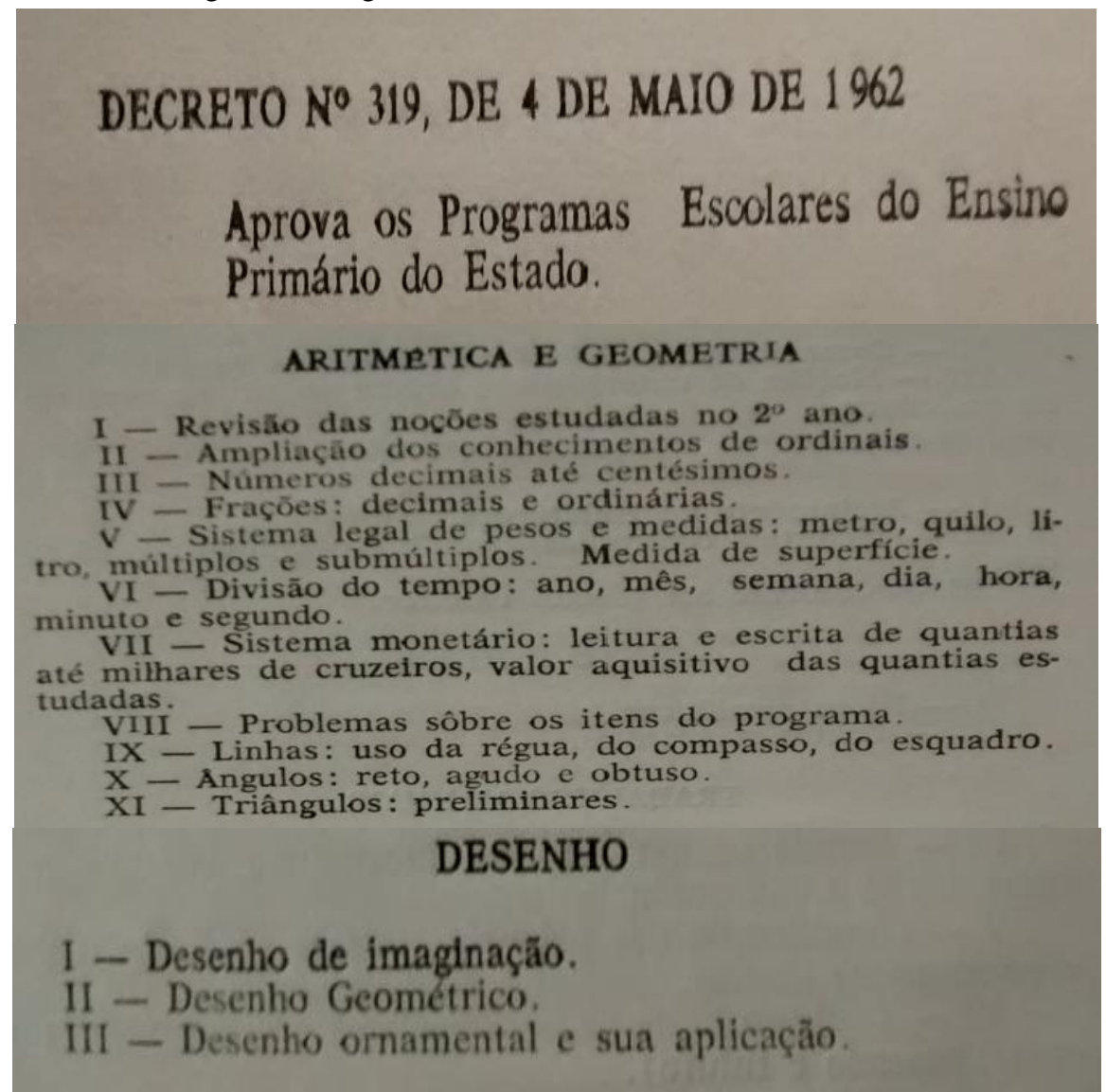

Fonte: Arquivo público de Mato Grosso.

Em 1963 cria-se o Centro de Aperfeiçoamento e Treinamento do Magistério, passando a oferecer o Curso de Férias para aprimoramento dos professores leigos, com caráter obrigatório, visando à melhoria do processo ensino-aprendizagem em todo Estado de Mato Grosso (ALMEIDA, 2010, p.79). A justificativa para o curso baseia-se nos dados levantados pela Mensagem Presidencial (1963, p.160) afirmando que no estado, mais de $60 \%$ dos professores em Mato Grosso eram leigos, sem a formação necessária para atuar no Magistério. Esses professores eram considerados pelo governo como um problema para o Estado, levando em conta os conhecimentos gerais que poderiam ter adquirido com a experiência, esses professores jamais estariam em condições de exercer integralmente as suas funções de mestres, sem os conhecimentos especializados da profissão docente (MARCÍLIO 1963, p.214). 
A criação das Escolas Normais no Brasil foi um pouco tardia se comparada aos demais continentes. Somente em 1835 foi instituída a primeira Escola Normal, situada na cidade de Niterói no Rio de Janeiro. A partir daí essas escolas se espalham pelo Brasil, com o objetivo de formar professores para atuar na escola primária.

\section{Vestígios da CUltura ESCOlAR: A FORMaÇão de NORMAlistas EM BarRa do GARÇAS}

A pesquisa na perspectiva da História Cultural, conforme Chartier (1990) está centrada nos indivíduos que fazem parte de um determinado evento. Para o autor, a pesquisa nesse aspecto não focaliza somente as construções de objetos, mas também, nos receptores desta cultura. Construir e desconstruir faz parte da investigação historiográfica. No dizer de De Certau (1982) quem descreve o que nunca foi dito toma para si o ofício de historiador.

Diversos estudiosos pesquisam sobre a historiografia da educação matemática e afirmam que para compor o cenário, utilizam-se dessa abordagem metodológica com apoio da história oral. As narrativas constituídas pela oralidade permitem que muitos signos sejam compreendidos acerca dos objetos enfocados numa investigação historiográfica. "O surgimento das novas tecnologias de registro, como o gravador portátil foi uma revolução similar àquela da imprensa, permitindo vislumbrar uma pluralidade de recursos para investigações" (GARNICA, 2012, p. 93).

No entanto, para reconstituir históricamente o processo educativo de Barra do Garças utilizou-se a historia oral para constituir elementos da nossa pesquisa. Neste cenário emerge a Escola Normal como espaço de formação das normalistas em territorio mato-grossense. A primeira Escola Normal de Mato Grosso foi criada no ano de 1837, como destaca Fin (2012) nos seus estudos.

Em 1837, no governo de José Antônio Pimenta Bueno, a província de Mato Grosso criou a primeira "Escola Normal Primária", por meio da Lei $\mathrm{n}^{\circ} 8$ de 5 de maio de 1837. Nesta época, quem governava a província de Mato Grosso era José Antônio Pimenta Bueno (1836 - 1838), o qual nomeou como diretor o Professor Joaquim de Almeida Louzada (2012, p. 20).

As dificuldades para dar início ao curso foram muitas, dentre elas a falta de formação. O professor Joaquim Louzada foi nomeado para atuar como diretor e professor da referida instituição. Com anuência do governo, Louzada foi encaminhado para Niterói no intuito de estudar o Ensino Normal e aprender o método Lancaster que tinha como proposição: $\mathrm{O}$ professor ensinava a lição a um "grupo de meninos mais amadurecidos e inteligentes". Os alunos eram divididos em pequenos grupos, os quais recebiam a lição através daqueles a quem 
o mestre havia ensinado. Assim um professor poderia "instruir muitas centenas de crianças" (EBY, 1978, p. 325).

Quando Louzada retornou ao Estado de Mato Grosso, a pretensão era criar a Escola Normal, porém, não foi o que ocorreu. O professor ficou pouco tempo na função e pediu demissão para assumir a secretaria do governo. Essa atitude trouxe desconforto ao governo que sofreu severas críticas em virtude do investimento feito no aperfeiçoamento de Louzada e sua imediata saída da educação.

Apesar das limitações, no dia 28 de outubro de 1840 foi instalada a primeira Escola Normal na Província de Mato Grosso. Porém, quatro anos depois foi extinta pela ausência de uma equipe de professores capacitados para exercerem o cargo. No período de 1844 a 1847 , Ricardo José Gomes Jardim governou a Província e fez o seguinte pronunciamento, justificando os motivos para a extinção da Escola Normal de Mato Grosso (MATO GROSSO, 1845).

No entanto, para contextualizar a primeira Escola Normal de Barra do Garças, buscouse acesso as fontes por meio de livros impressos e textos que discutem a temática. Surpreendentemente foi à constatação da ausência de fontes relativas ao funcionamento do curso no município. O material disponível ficou restrito às fontes orais de ex-alunas e aos registros no Livro Ata na qual consta o funcionamento do Curso Normal em 30 de setembro de 1961 pelas Irmãs Salesianas. A instituição foi elevada do $1^{\circ}$ para o $2^{\circ}$ Grau de Ensino, pela Lei 2636 de 03 de agosto de 1966 e posteriormente o Curso Normal foi autorizado pela Resolução $\mathrm{n}^{\circ} 26$ de 30 de maio de 1967, emitida pelo Conselho Estadual de Educação de Mato Grosso.

Pinto (2014) destaca que ao trabalhar na perspectiva histórica com fontes documentais, o primeiro desafio é assumir o ofício de historiador para investigar a história da cultura escolar por meio de fontes. Outro é a escolha de documentos que contenham vestígios da prática cultural (2014, p.31). A autora ainda esclarece sobre a importância de localizar e inventariar fontes históricas nos arquivos públicos, escolares e pessoais a fim de coletar depoimentos orais de ex-professores e ex-alunos, constituindo e organizando uma base de dados a ser disponibilizada a demais pesquisadores. Quanto à cultura escolar ela recomenda cautela ao pesquisar documentos que interessam a quem está investigando, pois esses são "portadores de normas, códigos e condutas escolares" (PINTO, 2014, p. 32).

Partindo dessas premissas, a pesquisa possibilitou conhecimento e reflexão a respeito da cultura escolar produzida pelo Instituto Santa Marta e as possíveis influências dessa cultura na formação de professoras primárias. A esse respeito Julia (2001) discute o conceito de cultura escolar sobre o esforço que o pesquisador tem que fazer para defini-lo: "tanto isso é verdade 
que esta cultura não pode ser estudada sem a análise das relações conflituosas que ela mantém, a cada período de sua história, com o conjunto das culturas que lhe são contemporâneas: cultura religiosa, política ou popular" (2001, p.10).

O Instituto Santa Marta localiza-se na cidade de Barra do Garças que no campo educacional segundo Simião (2006), "no início da década de 1930, o estado de Mato Grosso contava com 130 escolas rurais, uma delas em Barra do Garças tendo como primeira normalista a professora Gracildes Melo Dantas" (2006, p. 60-61). A autora durante a sua pesquisa tem a oportunidade de entrevistá-la que nos esclarece sobre a sensação dos primeiros dias como professora:

A sensação foi um bocadinho difícil, porque Barra do Garças era apenas um garimpo, quando foi nomeada[...] eu me deparei com uma classe de quase cem alunos de todo tipo. Não havia outra escola. Eles foram chegando, foram chegando, e eu não tinha coragem de dizer não [...] só tinha de ensinar desde o começo (SIMIÃO, 2006, p. 61 62).

No início do processo de escolarização, o município teve apoio das irmãs salesianas e segundo Simião (2006), a primeira Escola foi criada no ano de 1933 recebendo o nome de seu fundador Antônio Cristino Côrtes, porém, os alunos do ensino primário eram atendidos nas próprias residências e somente em 1949, a escola passa a ter sede própria.

Durante a pesquisa, a atual diretora do Instituto, Irmã Maria Eliete de Sousa concedeu informações relevantes sobre o pioneirismo das salesianas na educação de Barra do Garças.

\begin{abstract}
Em 1956, a Irmã Diva Pimentel (Diretora da Instituição), em companhia das Irmãs Joaquina Figueiredo e Maria Bethy Pires, pioneiras no processo educacional da cidade e pertenciam a Congregação das Irmãs Salesianas vinculadas a Casa Maria Auxiliadora, vinda do município de Araguaiana/MT. Instalaram-se na cidade de Barra do Garças, após oito anos de sua emancipação com o intento de dirigir a escola, permanecendo na gestão da instituição até 1970 (Entrevista à Irmã Maria Eliete de Sousa concedida em 12 de agosto de 2017).
\end{abstract}

Neste contexto, as Irmãs Salesianas tiveram papel fundamental na oferta educacional para os moradores barra-garcenses, como destaca o relato, chegam à cidade, após oito anos de sua emancipação e no ano de 1967 fundaram o Instituto Santa Marta, a primeira Escola Normal de Barra do Garças, no interior de Mato Grosso.

No entanto, buscou-se vestígios acerca da preservação da memória do Instituto Santa Marta, entendendo-a como indicativo de uma época importante enquanto fonte de dados históricos, por reconhecer que a escola é um espaço de domínio que favorece as relações entre as pessoas. Assim como a maioria dos espaços escolares, segundo a Irmã Maria Eliete, não há registros do passado. Afirma que são raras as instituições de ensino que conservam e preservam 
os registros escolares. Nas pesquisas históricas esse modo de investigação a história oral tem sido muito utilizada, até pela dificuldade de encontrar vestígios do passado ${ }^{3}$.

Julia (2002) sublinha que as ações de cunho educativo e cultural são aprendizados que na maioria das vezes não deixam rastros, tornando o processo de busca uma tentativa de identificar indícios do objeto de investigação, para chegar ao lugar traçado. O que acontece na escola, na sala de aula, nas práticas pedagógicas, livros didáticos e na formação de professores não estão desvinculados do social que o produz e, portanto, determina o que se concretiza ou não no ato pedagógico. Desta forma, o trabalho docente configura-se como uma atividade pertencente a um gênero profissional, que extrapola o espaço físico da sala de aula.

No entanto, o que se constatou durante a investigação é que na instituição pesquisada a normativa que regulamente a incineração dos documentos após cinco anos, prevalece sobre a importância da memória.

A Professora Sádia Luciana da Rocha Muniz, ex-aluna de Magistério e atualmente coordenadora da Educação Infantil na referida instituição, contribuiu com seu depoimento, rico em detalhes que contemplam vários fatos ocorridos. Relatou a situação precária em que a escola se encontrava no início de tudo e enfatizou que a sociedade barra-garcense sempre apoiou o trabalho dirigido pelas irmãs salesianas.

\begin{abstract}
As irmãs sempre reconheceram a ajuda que recebeu da sociedade barra-garcense. As autoridades federais, estaduais e municipais demonstravam seu apoio nomeando as freiras para conduzirem o ensino e participando em muitas atividades da escola. Também fizeram doações do terreno e recursos financeiros para a construção do prédio escolar, apoio didático aceitando e renovando convênio para manutenção da Instituição (Professora Sádia Luciana da Rocha Muniz, entrevista concedida em setembro de 2017).
\end{abstract}

A partir de 1967, a Escola Normal foi oficialmente implantada no município passando a ofertar o Curso para a Formação de Professores Primários. A vinda das Irmãs Salesianas para Barra do Garças faz parte do projeto de expansão do Ensino Normal em Mato Grosso e tem uma grande contribuição para a formação de professores da escola primária naquela região.

Barros (2011, p.370) outorga o conceito de memória coletiva àquela realizada com pausas, conquanto se destruiriam naturalmente por serem “[...] disfarçáveis em continuidade. Deste modo, ela (memória coletiva) assegura a sensação humana e social de unidade e permite que se atravessem mesmo os períodos históricos mais transformadores." Neste sentido, conhecer a cultura disseminada pelo Instituto Santa Marta ao longo dos anos é de extrema

\footnotetext{
${ }^{3}$ Devido ao tratamento que o Brasil dá à memória de modo geral e em particular na educação, em Mato Grosso, por exemplo, livros didáticos, diários de classes são incinerados após cinco anos ou quando alcança seu objetivo na escola.
} 
importância para compreendermos a formação das Normalistas que ministravam aulas para os alunos da escola primária na cidade de Barra do Garças.

\subsection{O ENSINO DE GEOMETRIA NO INSTITUTO SANTA MARTA}

Devido às dificuldades de acesso às fontes documentais foi primordial a utilização da história oral por meio dos depoimentos de cinco protagonistas ex- alunas do Curso Normal e posteriormente como professoras normalistas. Ao refletir as práticas de ensino, a história cultural, segundo Pinto (2014) é um lugar de excelência cheio de códigos conexos para serem compreendidos na história das disciplinas escolares. Porém, a história das práticas culturais é a mais complexa de reconstruir, como ressalta Julia (2001):

São práticas que não deixam traços. Entretanto, reconhecendo a restrição da localização das produções escolares, o historiador recomenda "fazer flecha com qualquer graveto", recomendando analisar diversos materiais, sejam anais escolares, de alunos e professores, sejam os que estejam em livros didáticos, fontes que poderão ser comparadas com reformas educacionais e programas prescritos para o ensino, no intento de produzir história de uma disciplina, advertindo que os textos normativos sempre precisam nos remeter às práticas (JULIA, 2001, p. 17).

O artigo de Julia, "A cultura escolar como objeto histórico" (2001) publicado em 1995 e traduzido para o português recentemente, tem sido muito citado em pesquisas, no cenário nacional e internacional. "Apesar da proximidade das formulações, um interesse pelas culturas infantis como integrantes da cultura escolar apareceu na segunda versão, matizando a ênfase conferida anteriormente ao que poderíamos chamar culturas docentes" (FILHO; GONÇALVES; VIDAL; PAULILO, 2004. p 143).

Julia (2001) evidencia que tanto os preceitos escolares quanto as práticas docentes não podem ser analisadas sem levar em conta os personagens que atuam nas escolas. Para o autor, eles são chamados a seguir esses códigos, e se apropriar dos aparelhos pedagógicos que devem ser investidos de possibilidades para os professores primários. No dizer do autor:

\footnotetext{
Mas, para além dos limites da escola, pode-se buscar identificar, em um sentido mais amplo, modos de pensar e de agir largamente difundidos no interior de nossas sociedades, modos que não concebem a aquisição de conhecimentos e de habilidades senão por intermédio de processos formais de escolarização (JULIA, 2001, p. 11).
}

Atualmente as protagonistas da pesquisa são professoras aposentadas com idade entre 60 e 70 anos, com exceção de uma delas que ainda leciona no Instituto. Iniciaram os estudos na Escola Normal no ano de 1975 e concluíram em 1977. Todas vivenciaram um período importantíssimo para história da educação em Barra do Garças.

A entrevista possibilitou identificar como eram as aulas de Matemática e como a geometria era apresentada no currículo escolar. Além dos depoimentos, teve-se acesso ao diário 
de uma ex-aluna do Instituto Santa Marta, professora da escola pública primária e um pequeno acervo de fotos e documentos pessoais (escolares) que serviram de sustentação para a pesquisa.

As professoras relataram a forma como estudaram geometria na escola normal e tecem comentários acerca da cultura escolar vigente nas décadas de 1960 a 1970. As depoentes contribuíram sobremaneira na educação Barra-garcense e seus depoimentos foram constituindo elementos para a compreensão da cultura escolar do período delimitado da pesquisa.

Optou-se por organizar as entrevistas por blocos, tendo em vista que as perguntas são as mesmas para todas, e foram realizadas individualmente com cada uma delas. A Prof. ${ }^{\text {a }}$ Madalena Albuquerque fez o Magistério e sempre trabalhou na Instituição. Mesmo aposentada, continua atuando como docente. A professora Odília Flores ex-aluna e professora primária aposentada, antes do início oficial da entrevista, lembrou com saudosismo as aulas de geometria. Afirma ter afinidade e se identifica muito com a geometria: "Amo geometria, pena que as escolas até hoje não valorizam esse conteúdo”. Seu relato revela um misto de decepção pelo descaso e satisfação de aprender e ensinar geometria para seus alunos.

Perguntou-se às professoras como era estudar no Instituto Santa Marta e como era a cultura da escola, tendo em vista que a Instituição era dirigida pelas freiras. A professora Edina Santos começou narrando que estudou no Instituto Santa Marta na década de 70 e sua mãe queria que se tornasse uma boa professora. Segundo o depoimento, naquele tempo por ser uma escola de religiosas a maioria das professoras eram freiras, então havia muita disciplina por parte dos estudantes e o lado religioso era o mais trabalhado. A depoente afirma que o Instituto funcionava em forma de internato para meninas que não tinha família na cidade e iam para casa somente no período de férias.

A professora Natalice Marcolan também relata que estudou no Instituto Santa Marta na década de 60, concluindo o Magistério no ano de 1969. Destacou que sempre estudou no colégio de freiras e segundo o depoimento, as jovens desde cedo já eram encaminhadas para o magistério. Na época existiam apenas dois cursos para o $2^{\circ}$ grau: o Magistério e o Técnico em Contabilidade. Afirma que desde criança, suas brincadeiras eram sempre de professora. e destaca que as irmãs salesianas conduziam as normas disciplinares e religiosas de forma muito rígidas, as atividades culturais eram sempre voltadas para o catolicismo e as visitas das autoridades religiosas eram sempre festivas e com apresentações dos alunos. Declara ainda que o curso de Magistério era muito bom e a formação que recebiam transmitia muita segurança para assumirem a sala de aula e considera melhor que curso a Pedagogia nos dias atuais. 
Trazendo a existência a materialidade, os relatos permitiram não apenas a percepção dos conteúdos ensinados, mas o entendimento do conjunto de afazeres ativados no interior da escola. É possível ainda considerar que o testemunho implica em identificar as marcas que as práticas orais tenham deixado no espaço da folha de caderno, da prova dentre outros. As relações orais se produzem na escola, a partir do contato dos sujeitos escolares com objetos, móveis, estrados, relógios, globos, crucifixo dentre muitos outros e também com a sala de aula, pátio, corredor, biblioteca (VIDAL, 2009, p.31).

Questionada sobre como eram as aulas de Matemática e se havia conteúdos de geometria no livro didático da época a ex-aluna Madalena Albuquerque respondeu:

Sim, o professor tinha livro de matemática e utilizava o livro didático, mas não participavam da escolha. Os livros eram impostos a nós e os conteúdos: as quatro operações com a prova dos nove. No final do livro a geometria com o nome das figuras geométricas - linha reta e ângulos. Eu fui obrigada a aprender, pois trabalhava na $4^{\mathrm{a}}$ série e naquela época, os professores davam todas as matérias. Só na $4^{\mathrm{a}}$ série que eu pedi ajuda para os professores de matemática nas figuras de 8 e 11 lados. (Prof $^{a}$ Madalena Albuquerque, depoimento e fotos concedidas em 12/11/2017).

Posteriormente, as perguntas foram direcionadas para as entrevistadas como professoras da escola primária. Perguntou-se de que forma elas ensinavam geometria, se tinham dificuldades em ensinar e como os alunos aprendiam.

Quando me tornei professora, no livro de matemática tinha uma unidade de geometria no final do livro. E como a gente dava mais importância para as três primeiras unidades, então às vezes era bem pouco visto a área de geometria. Hoje a gente sabe o quão importante é talvez ministrar primeiro esse conteúdo que a gente pode já ir fazendo na prática e colocando os outros conteúdos dentro da geometria (Professora Natalice, depoimento concedido em 08/11/17).

Ao serem indagadas se tinham dificuldades para ensinar geometria no primário, quais os recursos utilizados, a metodologia adotada, que conteúdos e como os alunos aprendiam:

Tínhamos dificuldades, porque não estudamos geometria no Curso Normal. Quando nos tornamos professoras além de não dominar o conteúdo, não possuíamos muitos recursos materiais para trabalhar retas, figuras geométricas, curvas, figuras circulares, círculo, triângulo, retângulo, quadrado etc. Também não tínhamos cursos de formação especifico em geometria, para nos auxiliar. Quanto aos recursos eram disponibilizados: bolas, grandes e pequenas, cubos tipo almofada, bambolê, cordas para pular, além das atividades desenvolvidas em sala de aula (Professora Edina Queiroz, depoimento concedido em 08/11/17).

O que se percebe nos fragmentos das falas é que a geometria não era vista como um conteúdo significativo. Os relatos evidenciaram que algumas das depoentes não sabiam se tinham estudado geometria, afirmaram também que nunca tiveram formação específica sobre esse conteúdo para ensinar seus alunos, sendo esse um dos elementos básicos das dificuldades que elas tinham. 
Durante a conversa, foi perguntado se no período em que estudava o Instituto Santa Marta utilizava algum livro didático. Uma delas, a ex-aluna Natalice respondeu que sim, porém, as lembranças eram vagas em relacão ao nome do livro. Depois se verificou que na biblioteca da escola havia o livro de Theobaldo Miranda Santos, Metodologia do Ensino Primário. No dizer da ex-aluna Natalice:

\begin{abstract}
As aulas eram monótonas, focalizando o conteúdo apresentado sem nenhuma forma criativa. Na época a professora de matemática nos solicitava para ir ao quadro negro. O livro de geometria tinha capa amarela, não lembro o nome, tinha o manual do professor e os livros de exercícios dos alunos. Sempre gostei, sem dificuldades (Prof ${ }^{a}$ Natalice Marcolan, depoimento concedido em 27/11/2017).
\end{abstract}

O livro mencionado por Natalice revela que o autor Theobaldo Miranda Santos participou efetivamente dos movimentos acerca da política, da educação, nas questões éticas, morais ou religiosas. "Todas as estratégias da Igreja fazem parte de uma intenção de construir um projeto estratégico de intervenção na cultura pela formação do professor. (ALMEIDA FILHO, 2008, p. 3)".

Ao que tudo indica, sua obra seria a estratégia capaz de representar o movimento das concepções cristãs católicas (ALMEIDA FILHO, 2008). Theobaldo Miranda Santos foi referência em Mato Grosso e demais regiões do país na elaboração de livros didáticos relacionados às diversas áreas de conhecimento, sendo considerado um modelo a ser seguido nos moldes dos Programas dos principais Institutos de Educação e Escolas Normais do país.

Figura 2 - Livro Metodologia do Ensino Primário.

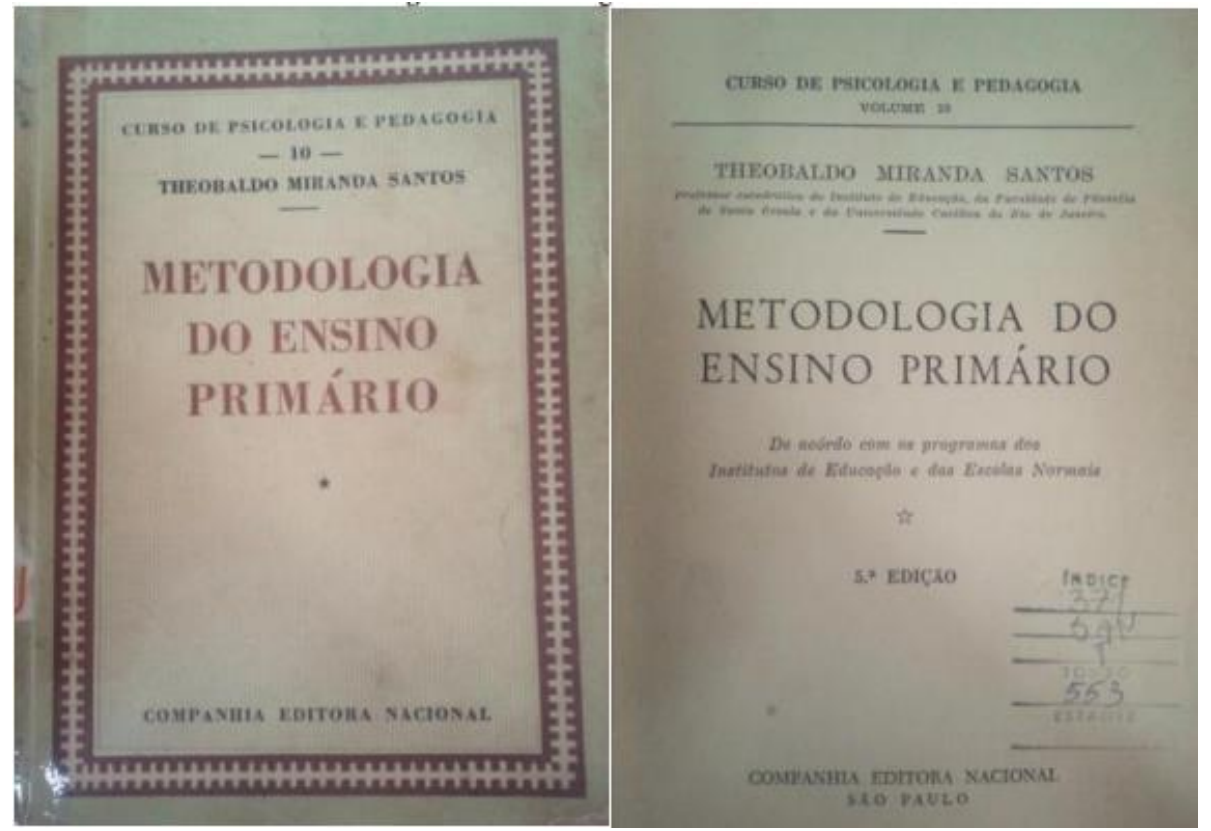

Fonte: Acervo da Biblioteca do Instituto Santa Marta, 2017. 
Ory (2004 apud Pinto, 2014, p.138) ressalta que uma pesquisa quando se vale dos livros didáticos, não se pode omitir a importância concedida ao mensurável. De acordo com Pinto (p.139) outro aspecto considerado fundamental na construção metodológica da pesquisa é quando há diálogo do pesquisador com a materialidade escolar para “enxergar” vestígios, pistas, sinais que contribuem na construção da resposta à questão central formulada, aspecto que irá permitir a "descrição densa" (GEERTZ, 1989) e garantir mais inteligibilidade da rede estabelecida.

A professora Madalena Albuquerque, contribuiu sobremaneira quando esclarece que quando estudava, o ensino era mais rígido, sem liberdade de falar, mas era de qualidade e não precisava de escolas particulares, além de ter alimentos nas mesas. Hoje, segundo Professora Madalena sublinhou o amor pela profissão e afirma que algumas coisas se perderam e não há o investimento necessário para o ensino público. Quanto ao livro didático, afirmou que a professora fazia uso em sala de aula.

A professora Crisodi também relatou sobre o uso do livro didático de Matemática:

Quando ministrava aulas, a gente tinha sim o livro didático, como hoje. Era muito usado pelos professores em sala de aula. Eu também já adquiri experiência pegando o livro que era usado pela própria escola. Quanto ao ensino da geometria não me lembro como a gente aprendia, mas eu sei que o magistério tinha o objetivo de nos ensinar como trabalhar as primeiras séries iniciais do ensino primário (Prof ${ }^{a}$ Crisodi Rezende, depoimento concedido em 09/10/2017).

Ficou evidenciado que as entrevistadas ainda veem a Matemática como um mito, em alguns momentos, a geometria como uma disciplina "desnecessária" o que dificulta e muito as possibilidades de um efetivo ensino. Esse fator contribuiu para a ausência da geometria nos conteúdos trabalhados, como está posto na figura 3, o Diário de Classe, de uma ex-aluna do Instituto Santa Marta e professora primária. 
Figura 3 - Diário de Classe - $4^{\mathrm{a}}$ Série - Prof ${ }^{\mathrm{a}}$ Gilvone Miguel , 1985
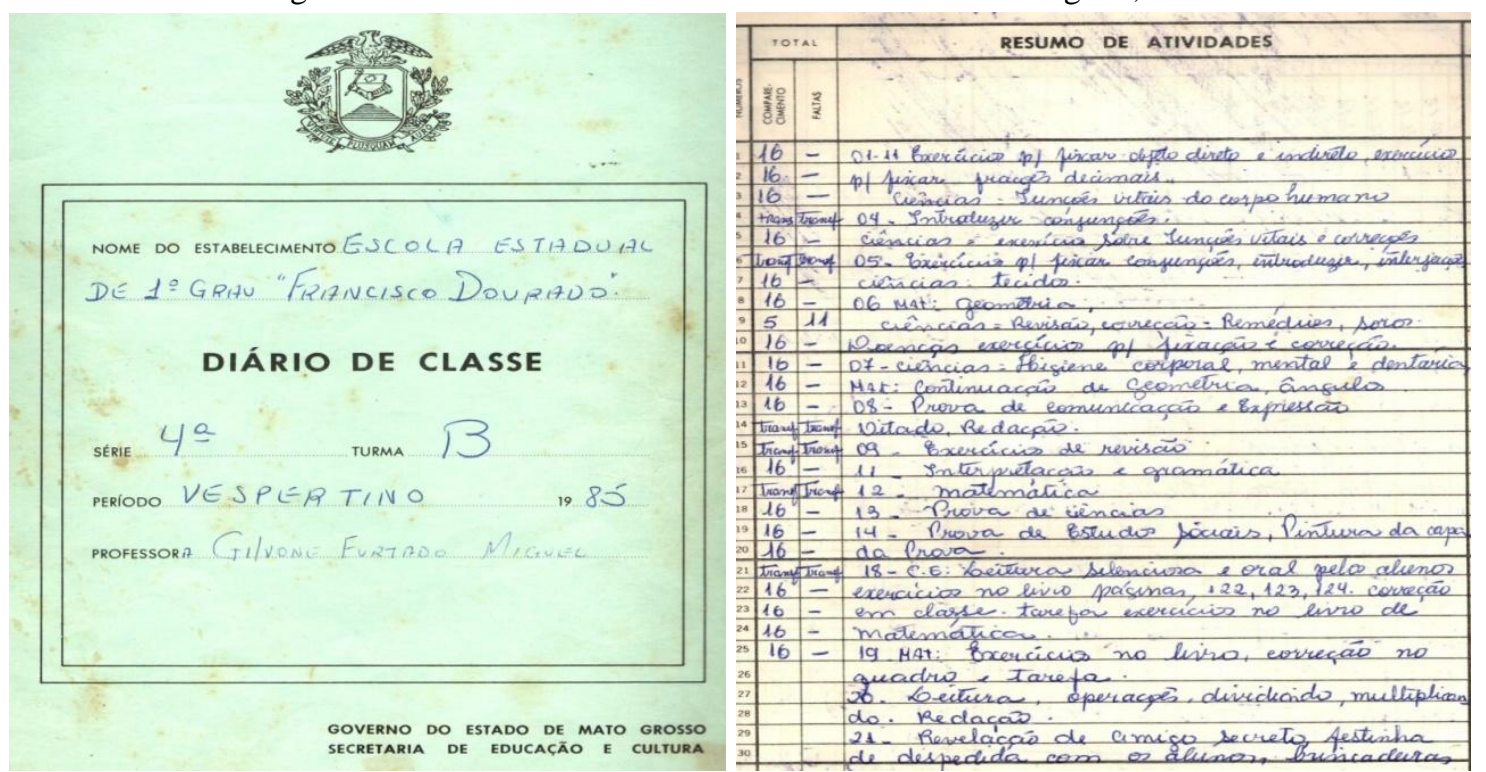

Fonte: Escola Estadual de $1^{\circ}$ Grau Francisco Dourado - Barra do Garças/MT.

Com ausência de fontes documentais do Instituto Santa Marta e o desejo de analisar os registros vinculados ao recorte temporal da pesquisa conseguimos inventariar 10 diários na Escola Estadual de $1^{\circ}$ Grau Francisco Dourado, datados de 1985, que foram minuciosamente analisados e apenas um constava o registro de "Introduzir Geometria" nos dias 06 e 07/11/1985. Ao analisarmos os diários na íntegra fica evidenciado que a geometria sempre foi fustigada das aulas na escola primária.

A esse respeito Zabalza (2004, p. 16) ressalta que "o bom de um diário, o que se torna um importante documento para o desenvolvimento pessoal, é que nele se possa contrastar tanto o objetivo descritivo como o reflexivo pessoal. Com isso, torna-se possível analisar a evolução dos fatos".

Analisando o diário, este não serviu somente para saber como a aula foi planejada e executada, mas também para que o historiador possa fazer uma reflexão sobre os conteúdos abordados. Dessa forma, "os diários podem variar tanto pelo conteúdo que recolhem como pela periodicidade com que são escritos e pela função que cumprem", ressalta Zabalza (2004, p. 15).

\section{CONSIDERAÇÕES FinaIS}

Com o intento de responder a questão norteadora "De que forma a geometria esteve presente na formação de professores primários do Instituto Santa Marta em Barra do Garças nas décadas de 1960 a 1980, buscou-se compreender por meio das fontes e depoimentos orais de protagonistas que vivenciaram esse momento, como esse conteúdo foi trabalhado durante a formação das normalistas. As fontes revelam o apoio incondicional das irmãs salesianas para o 
processo educacional do município e fica evidenciado a relevância do Instituto Santa Marta (1967) como a primeira Escola Normal de Barra do Garças, no interior de Mato Grosso, que possibilitou melhorar a qualidade do ensino na região.

Um aspecto que nos chamou a atenção foi a ausências de fontes do referido Instituto Santa Marta que poderiam constituir elementos mais significativos sobre a história do processo educativo da instituição, responsável pela formação de normalistas. No entanto, constata-se que provavelmente foram carbonizados, conforme a normativa que regulamenta a incineração dos documentos após cinco anos, que prevalece sobre a importância da memória dos arquivos escolares.

A esse respeito buscou-se informações na Assessoria pedagógica de Barra do Garças/MT a qual disponibilizou uma Portaria que legitima e dá legalidade às incinerações dos arquivos escolares. De acordo com a Portaria No 251/2005/GS/SEDUC/MT, publicada no Diário Oficial de 29 de dezembro de 2005, consta uma Tabela de Temporalidade de Documentos Fins, que traz as orientações sobre a incineração de documentos que desvendam a cultura escolar.

Desse modo, os historiadores são responsáveis pelas escolhas feitas e fazer pesquisa na perspectiva histórica, depende do estado da documentação, no caso, não havia toda documentação disponível. Contudo, inventariamos dez diários de outra unidade escolar do munícipio que a época recebia a mesma formação e orientação pedagógica para a realização dos trabalhos, encontravam-se prontos para serem incinerados (1983 a 1985). Um dos diários é de uma ex-aluna do Instituto Santa Marta que antes tivemos a oportunidade de manusear e digitalizar as fontes inerentes ao objeto de pesquisa.

Diante dos entraves e dificuldades que o pesquisador encontra no percurso metodológico, a pesquisa possibilitou-nos constatar por outros meios (documentos e depoimentos de protagonistas) que a geometria sempre foi preterida, tanto no período em que as entrevistadas ainda eram estudantes da Escola Normal e posteriormente quando se tornaram normalistas e atuaram como professoras do ensino primário. As razões são muitas e começa pela complexidade dos conteúdos propostos pelo Movimento da Matemática Moderna (MMM) na década de 1960, quando se deu preferência ao rigor matemático. Conforme Muniz (2017), os professores sentiam-se despreparados para ministrar suas aulas e muitos suprimiam esses conteúdos do planejamento.

Pode-se constatar por meio dos relatos que no Curso Normal algumas das depoentes declararam que tinham dificuldades para ensinar geometria, porque não aprenderam esse 
conteúdo no magistério e ainda destacaram que "as aulas eram monótonas, focalizando o conteúdo apresentado sem nenhuma forma criativa (MARCOLAN, 2017)".

Os relatos destacam também que os livros eram impostos e os conteúdos relacionados às quatro operações, exigia a prova dos nove. Ao final do livro, a geometria era apresentada com o nome das figuras geométricas - linha reta e ângulos. Além de trabalhar todas as matérias, os professores eram obrigados a aprender todo o conteúdo, pois trabalhavam no ensino primário.

Somente na $4^{\mathrm{a}}$ série, pediam ajuda para os professores de Matemática nas figuras representadas por 8 e 11 lados, porque não tinham domínio de conteúdo. Com as mudanças curriculares no período, houve uma discriminação em relação à geometria quando passou a ocupar os últimos capítulos dos livros didáticos. Diante dos fatos, fica evidente o porquê da Geometria ainda ser uma das matérias mais secundarizadas da Matemática.

Outra fonte analisada foi o Diário de Classe do ensino primário da década de 1980. Nele constatam-se dois registros superficiais, no mês de novembro, relacionados os conteúdos de geometria. Considerando as deficiências de formação relatadas pelas participantes, ressalta-se a importância da formação continuada dos professores que atuam em sala de aula, tanto em conteúdos de base nos quais persistam as dificuldades, quanto em conhecimento de novas tendências e teorias que contribuam com o ensino da geometria. Com isso, torna-se possível minimizar as dificuldades e a situação de abandono em que se encontra, até hoje, o ensino de geometria.

Nesta perspectiva, a pesquisa constatou a fragilidade da presença da geometria na formação das professoras entrevistadas. Esse contexto permitiu compreender as dificuldades em ensinar geometria, reveladas durante suas narrativas. Desse modo, faz-se necessário uma reflexão sobre a formação inicial e continuada de professores para que sejam viabilizados recursos para ensinar geometria, ressaltando sua importância no cotidiano das pessoas, bem como, a valorização dos elementos que constituem a cultura escolar de outrora, trazendo novas compreensões e interpretações, na tentativa de responder várias questões que instigam os pesquisadores do campo da Educação Matemática.

\section{REFERÊNCIAS}

ALMEIDA, Laura I. M. V. de. Ensino de matemática nas séries iniciais no estado de Mato Grosso (1920-1980): uma análise das transformações da cultura escolar. 2010. 230 f. Tese (Doutorado em Educação). Pontifícia Universidade Católica do Paraná, Curitiba, 2010. 
ALMEIDA FILHO, Orlando José de. A estratégia da produção e circulação católica do projeto editorial das coleções de Theobaldo Miranda Santos: (1945-1971). Tese (Doutorado em Educação História Pólítica Sociedade). Pontifícia Universidade Católica de São Paulo, 2008.

BARROS, José D’Assunção. Memória e história: uma discussão conceitual. In: Tempos históricos Dossiê: História, cinema e música. Universidade Estadual do Oeste do Paraná. Campus Marechal Cândido Rondon. Centro de Ciências Humanas, Educação e Letras. Colegiado do curso de História - v.15, N. 01. Ano XIII. $1^{\circ}$ semestre. Marechal Cândido Rondon: EDUNIOESTE, 2011. (p. 369-400).

BITTAR, Mariluce. A educação superior na região sul de Mato Grosso e a influencia salesiana - décadas de 60 e 70. Campo Grande: UCDB. Relatório de pesquisa, 2001. Disponível em: https://www.ufmt.br/revista/arquivo/rev21/mariluce.html.

BITTENCOURT, Circe Fernandes. Disciplinas Escolares: história e pesquisa. In: OLIVEIRA, Marcus; RANZI, Serlei (Org.). História das Disciplinas Escolares no Brasil: contribuições para o debate. Bragança Paulista: EDUSF, 2003. P. 9-38.

BLOCH, Marc. Apologia da História ou o Ofício do Historiador. Rio de Janeiro: Jorge Zahar Ed., 2001.

BRASIL. Lei de 15 de outubro de 1827. Manda crear escolas de primeiras letras em todas as cidades, villas e logares mais populosos do Império. Disponível em:

http://www2.camara.gov.br/legislacao/publicacoes/doimperio.

CASTRO, Francisco Mendes de Oliveira, E ed. A Matemática no Brasil. Campinas, S.P.Editora da Unicamp, 1999.

CHARTIER, Roger. A História Cultural: entre práticas e representações. Tradução Maria Manuela Galhardo. Rio de Janeiro: Bertrand Brasil,1990.

CHERVEL, André. História das disciplinas escolares: reflexões sobre um campo de pesquisa. Teoria \& Educação, Porto Alegre, n. 2, p.177-229, 1990.

DE CERTEAU, Michel de. A escrita da história. Rio de Janeiro, RJ: Forense Universitária, 1982.

EBY, Frederick. História da educação moderna: séc. XVI/séc. XX. 5 ed. Porto Alegre: Globo, 1978.

FAINGUELERNT, E.K. O Ensino de Geometria no $1^{\circ}$ e $2^{\circ}$ Graus. A Educação Matemática em Revista. SBEM, nº 4, p.45. Blumenau. $1^{\circ}$ semestre, 1995.

FERNANDES Juliana Chiarini Balbino; BORGES Rosimeire Aparecida Soares. O Ensino de Primeiro Ano Primário em Tempos de Escola Ativa: a geometria nos programas brasileiros. Revista Exitus, Santarém, PA. V. 5 nº 2. Exitus. Pará, 2015, p. 194-213.

FILHO, Luciano Mendes de Faria; GONÇALVES Irlen Antônio; VIDAL Diana Gonçalves; PAULILO, André Luiz. A cultura escolar como categoria de análise e como campo de investigação na história da educação brasileira. Educação e Pesquisa, São Paulo, v.30, n.1, p. 
139-159, jan./abr. 2004. Disponível em: https://www.scielo.br/pdf/ep/v30n1/a08v30n1.pdf. Acesso dia 08 de agosto de 2020.

FIN, Maria Teresinha. Apropriação das Ideias Escolanovistas no Curso de Formação de Professores em Mato Grosso (1910-1937). Dissertação Cuiabá - MT 2012.

GARNICA, Antonio Vicente Marafioti; Souza Luzia Aparecida de. Elementos de História da Educação Matemática. São Paulo: Cultura Acadêmica, 2012. Disponível em: https://repositorio.unesp.br/bitstream/handle/11449/109211/ISBN9788579832932.pdf?sequen $\underline{\text { ce}=1 \& i s A l l o w e d=y}$ Acesso em 09 de agosto de 2020 .

GEERTZ, Clifford. A Interpretação das culturas. Rio de Janeiro: Guanabara, 1989.

GRAMSCI, Antônio. Concepção dialética da história. 3 ed. Rio de Janeiro: Civilização Brasileira,1973.

JULIA, Dominique. A cultura escolar como objeto histórico. Tradução de Gizele de Souza. Revista Brasileira de História da Educação. Campinas, n.1, jan/jun.2001, p.9-43.

JULIA, Dominique. Disciplinas escolares: objetivos, ensino e apropriação. In: LOPES, A.; MACEDO, E. (Org.) Disciplinas e integração curricular: história e políticas. Rio de Janeiro: DP\&A, 2002, p. 37-72.

MARCÍLIO, Humberto. História do ensino em Mato Grosso. Cuiabá - MT, Secretaria de Educação, Saúde e Cultura, 1963.

MATO GROSSO. Mensagem Presidencial - Presidente do Estado á Assembleia Legislativa de Mato Grosso. Arquivo Público de Mato Grosso, Cuiabá - MT, 1963.

MATO GROSSO. Presidência da Província. Discurso. O Presidente da Província, Ricardo José Gomes Jardim, apresenta discurso na abertura da sessão ordinária da Assembléia Legislativa Provincial. Cuiabá, 1 mar. 1845. NDIHR - Microfilme rolo 1 (R.P.P.), 18351864, p. 17-19.

MATO GROSSO. Lei Provincial no 8, de 05 de maio de 1837. Cuiabá 5 de Maio de 1837. Disponível em: https://www.al.mt.gov.br/storage/webdisco/leis/lim-8-1837.pdf Acesso em: $13 / 11 / 2019$.

MENESES, Ricardo Soares de. Uma história da Geometria escolar no Brasil: de disciplina a conteúdo de ensino Dissertação de Mestrado, São Paulo: PUC, 2007. Disponível em: https://tede2.pucsp.br/handle/handle/11203 Acesso em: 08/08/2020.

MISSÃO EM NOTÍCIA. Colégios: a educação a serviço da cidadania. In: Boletim Salesiano. São Paulo: Editora Salesiana, ano 52, nº 2, março/abril de 2002.

MOCROSKY. Luciane Ferreira; MONDINI. Fabiane; ESTEPHAN. Violeta Maria. O ensino de geometria no Brasil: alguns aspectos da sua origem nos livros didáticos brasileiros. III Simpósio Nacional de Ensino de Ciência e Tecnologia. Ponta Grossa-PR. 2012. Disponível em: http://www.sinect.com.br/anais2012/html/artigos/ensino\%20mat/19.pdf. Acesso em: 08/08/2020. 
MUNIZ. Angelina Maria Cartaxo. Procedimentos utilizados por estudantes do nível médio técnico em problemas de semelhança de triângulos contextualizados e não contextualizados. Dissertação (Mestrado em Educação). UFRPE, 2017.

PINTO, Neuza Bertoni. História das disciplinas escolares: reflexão sobre aspectos teóricometodológicos de uma prática historiográfica. Revista Diálogo Educacional, Curitiba, v. 14, n. 41, p. 125-142, jan./abr. 2014.

REVEL, Jacques; CERTEAU, Michel de; JULIA, Dominique. A beleza do morto: o conceito de cultura popular. In: REVEL, Jacques. A Invenção da sociedade. Lisboa: DIFEL, 1989, p. 49-75.

SAVIANI, Demerval. História das ideias pedagógicas no Brasil. 3 ed. Campinas: Autores Associados, 2010.

SANTOS, Jamile Aparecida Saulino dos. Problemas de ensino e de aprendizagem em perímetro e área: um estudo de caso com professores de matemática e alunos de $7^{\mathrm{a}}$ série do ensino fundamental. 117 f. Dissertação (Mestrado em Educação) - Universidade Metodista de Piracicaba - Piracicaba/SP, 2011.

SANTOS, Elton Castro Rodrigues dos. Escolas reunidas mato-grossenses: as prerrogativas educacionais expressa no regulamento de 1927. XVIII ENDIPE Didática e Prática de Ensino no contexto político contemporâneo: cenas da Educação Brasileira. 2016, p. 8387 a 8398. Disponível em: https://www.ufmt.br/endipe2016/downloads/233_10198_36309.pdf Acesso em 11/11/2019.

SILVA Maria Celia Leme; VALENTE, Wagner Rodrigues (orgs). A geometria nos primeiros anos escolares: História e perspectiva atuais. Campinas, SP: Papirus,2014.

SIMIÃO, Regina Aparecida Versoza. O processo de profissionalização docente em Mato Grosso (1930-1960). Cuiabá, MT. EdUFMT, 2006.

TARDIF, Maurice. Saberes docentes e formação profissional. 9 ed. Petrópolis: Vozes, 2008.

TARDIF, Maurice. Saberes profissionais dos professores e conhecimentos universitários. Elementos para uma epistemologia da pratica profissional dos professores e suas consequências em relação à formação para o magistério. Revista Brasileira de Educação. 10 ed. Petrópolis, RJ: vozes, 2010.

VALENTE. Wagner Rodrigues. Considerações sobre a matemática escolar numa abordagem histórica. Cadernos de História da Educação - no. 3 - jan./dez. 2004. Disponível em: https://repositorio.ufsc.br/xmlui/bitstream/handle/123456789/160367/363-1269-1 PB.pdf? sequence $=1 \&$ isAllowed=y Acesso dia 07 de agosto de 2020.

VALENTE, Wagner Rodrigues. A matemática nos anos iniciais escolares em perspectiva histórico-comparativa. Hist. Educ. [Online] Porto Alegre v. 18 n. 44 Set./dez. 2014 p.7-8.

VIDAL, Diana Gonçalves. Escola Nova e Processo Educativo 500 anos de Educação no Brasil. 3 ed. Belo Horizonte: Autêntica, 2003, p. 497-517. 
VIDAL, Diana Gonçalves. No interior da sala de aula: ensaio sobre cultura e prática escolares. Currículo sem Fronteiras, v.9, n.1, 2009, p.25-41.

ZABALZA, Miguel Antoni. Diários de aula. Um instrumento de pesquisa e desenvolvimento pessoal. Porto Alegre: Artmed, 2004.

Recebido em: 14 de maio de 2020.

Aprovado em: 24 de agosto de 2020. 